\title{
Effect of soil-plant-animal mineral interactions in the genesis of puerperal haemoglobinuria in dairy animals
}

\author{
SS Randhawa 1, CL Arora 2, BP Joshi ${ }^{3}$ \\ 'Dept Vet Med ; 2Deptt Soils, PAU Ludhiana 141004, Punjab; ${ }^{3}$ COVSc \& AH, Mathura, India
}

Puerperal haemoglobinuria $(\mathrm{PH})$ is one of the endemic metabolic disorders in high yielding dairy animals and has been reported from many parts of the world including India. The present study was conducted to monitor the mineral alterations in plasma vis-à-vis their relationship with mineral status of soils and plants in disease prone areas of the Punjab State.

Blood samples from clinical cases of $\mathrm{PH}$, tentatively diagnosed in 82 dairy animals, were included for mineral analysis. The confirmation of $\mathrm{PH}$ was on the basis of centrifugation followed by microscopic examination of urine and blood samples. Blood samples from 32 healthy dairy animals were also analysed for establishing control values. Forage and soil samples were also collected from the farmer's fields and processed as per standard procedures.

Estimation of plasma minerals was carried out with atomic absorption spectrophotometer. However, Mo was estimated as per the method of Ellis and Olson (1950, Anal Chem, 22, 328330). Plant and soil extracts were analysed for simultaneous determination of minerals on inductably coupled argon plasma atomic emission spectrophotometer.
Plasma mineral profile of haemoglobinuric animals revealed significant $(\mathrm{P} \leq 0 \mathrm{05})$ decline in $\mathrm{P}(52 \%), \mathrm{Ca}, \mathrm{Cu}(64 \%)$ and $\mathrm{Mg}$ associated with significant increase in $\mathrm{Mo}, \mathrm{Zn}, \mathrm{Fe}, \mathrm{Na}$ and $\mathrm{K}$ contents as compared to those of healthy controls.

Hypophosphataemia was directly related to significantly $(P \leq 0.05)$ low levels of $P$ in soils $(8.94 \mathrm{ppm})$ and forages (2165 ppm) associated with a wider $\mathrm{Ca}$ : $\mathrm{P}$ in soils (41.36) and forage samples (5.74) from $\mathrm{PH}$ affected farms as compared to respective mean values of $P$ (32.41 and $3327 \mathrm{ppm})$ and $\mathrm{Ca}: \mathrm{P}(13.87,2.82)$ from $\mathrm{PH}$ free farms. The hypophosphataemia was also precipitated by high levels of plasma Mo through increased urinary and faecal excretion of $P$. Over 260 fold increase in plasma Mo was inversely related to resultant hypocupraemia which was ascribed to exclusive feeding of leguminous forages especially berseem (Trifolium alexandrinum $L$.) having low $\mathrm{Cu}$ and high $\mathrm{Mo}$ and $\mathrm{S}$ contents.

It was inferred that soil and forage samples from $\mathrm{PH}$ affected farms were low in $\mathrm{P}, \mathrm{Cu}$ and $\mathrm{Cu}$ : Mo but high in Mo, S, Al, Cd, Fe, Pb, Cr, $\mathrm{Ni}$ and $\mathrm{As}$ contents with a wider $\mathrm{Ca}: \mathrm{P}$ which resulted in development of hypophosphataemia and hypocupraemia and thus contributed in the genesis of haemoglobinuria. 